\title{
Pseudoxanthoma elasticum and statin prophylaxis
}

\author{
Friedrich C. Luft
}

Published online: 13 September 2013

(C) Springer-Verlag Berlin Heidelberg 2013

Pseudoxanthoma elasticum (PXE), or Grönblad-Strandberg syndrome, is an autosomal-recessive, or sometimes autosomaldominant, genetic disease that causes fragmentation and calcification of arterial elastic fibers in certain tissues. The skin, eyes, and blood vessels are prominently involved, and with increasing age, a premature form of atherosclerosis develops. PXE commonly affects the skin even in early childhood. Later, yellowish papular lesions form and cutaneous laxity affects the neck, axillae (armpits), groin, the inside parts of the elbows, and knees. Careful inspection of the axillae is helpful in establishing the diagnosis (Fig. 1a), coupled with a detailed funduscopic examination of the eye (Fig. 1b). PXE affects the retina through a dimpling of Bruch's membrane, which separates the blood vessel-rich layer of the retina from the pigmented layer. Breaks or cracks in Bruch's membrane create typical "angioid" streaks radiating from the optic nerve. Blood vessels penetrating Bruch's membrane may hemorrhage, thereby compromising vision. The principal clinical complaints involve the gastrointestinal tract and cardiovascular systems. Upper gastrointestinal bleeding may develop. However, the circulatory system is more commonly involved and intermittent claudication is a prominent feature. At later stages, coronary artery disease occurs, leading to angina pectoris and myocardial infarction at an early age [1]. Patients with clinical PXE have mutations in the ABCC6 gene, encoding the multidrug resistance protein 6 , an ATP-binding cassette subfamily $\mathrm{C}$ member also known as ABCC6. ABCC6 is the multispecific organic anion transporter $\mathrm{E}[2,3]$. The most common mutations, R1141X and 23-29del, represent about a quarter of the mutations in $A B C C 6[4,5]$.

\section{F. C. Luft $(\bowtie)$}

Experimental and Clinical Research Center, a joint cooperation between the Charité Medical Faculty and the Max-Delbrück Center for Molecular Medicine), Berlin, Germany

e-mail: luft@charite.de
$\mathrm{ABC}$ transporters are transmembrane proteins that utilize the energy of adenosine triphosphate (ATP) hydrolysis to carry out certain biological processes including translocation of various substrates across membranes and non-transport-related processes such as translation of RNA and DNA repair. The transported substrates include metabolic products, lipids and sterols, and drugs. $\mathrm{ABC}$ transporters are involved in tumor resistance, cystic fibrosis, and a range of other inherited human diseases along with both bacterial (prokaryotic) and eukaryotic (including human) development of resistance to multiple drugs. Interestingly, mutations in ABCC6 are associated with premature atherosclerosis, even in patients without PXE [6]. However, the function of ABCC6 and how the mutations lead to the phenotype is unknown [7].

In this issue, Guo and colleagues present their data on $A b c c 6$ gene-deleted (-I-) mice [8]. These mice develop extensive mineralization of the arterial tree and disturbances in Bruch's membrane very similar to those observed in PXE. The authors found that by age 12 weeks, the $A b c c 6^{-/-}$mice had increased total cholesterol and triglyceride plasma concentrations. Treatment of the mice with atorvastatin at low $(0.01 \%$ of diet weight) and high ( $0.4 \%$ of diet weight) doses beginning at age 4 weeks reduced lipid values and also ameliorated vascular calcification, particularly at the higher dose, whereas beginning treatment at 12 weeks, when calcification had already occurred, was not helpful. Guo et al. estimate that the higher dose of atorvastatin would be equivalent to about $110 \mathrm{mg} /$ day in humans [8]. The higher dose of atorvastatin reduced triglycerides by about $50 \%$ and cholesterol about $27 \%$. The control mice had total cholesterol of about $80 \mathrm{mg} / \mathrm{dl}$, while triglycerides were about $50 \mathrm{mg} / \mathrm{dl} . A b c c 6^{-/-}$mice had higher values at 100 and $80 \mathrm{mg} / \mathrm{dl}$, respectively. The authors recognized the potential clinical relevance of their findings and contacted patients in the PXE International Patient Registry. A total of 1,747 patients were asked about statin use. Five hundred thirty-nine responders indicated a $24 \%$ statin ingestion, 


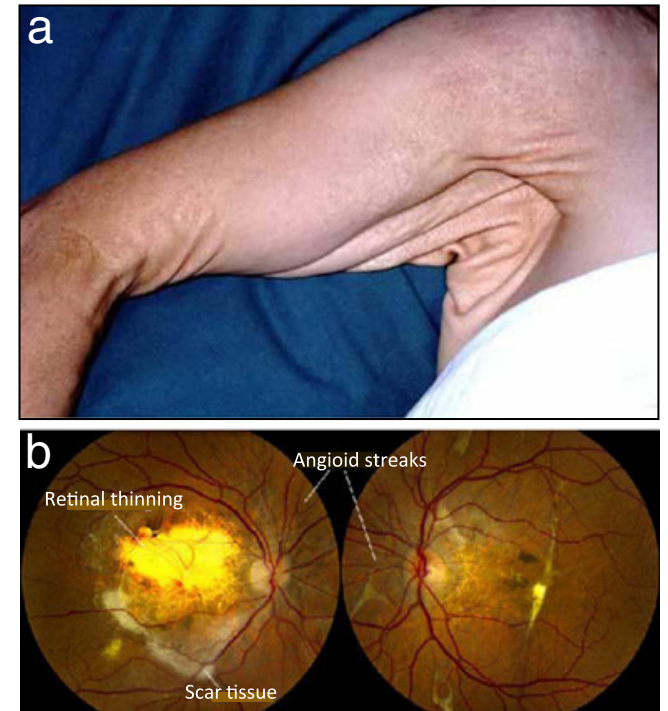

Fig. 1 a Typical axillary appearance of a PXE patient is displayed (image courtesy of http://www.patient.co.uk/doctor/PseudoxanthomaElasticum.htm). b Funduscopic appearance of the right and left eyes from a PXE patient showing angioid streaks, retinal thinning, and scarring (image courtesy of http://www.nei.nih.gov/eyeonnei/snapshot/ archive/060809.asp)

while $6.7 \%$ reported previous usage. The ages of these patients and at what age they began ingesting statins are not known.

Wild-type mice are not a good model for atherosclerosis, and the genes encoding apolipoprotein E or the LDL receptor must be eliminated along with adjustment of the diet before mice develop atherosclerosis. However, $A b c c 6^{-/-}$mice do not model atherosclerosis, but rather vascular calcification. What small role the reductions in total cholesterol or triglycerides contributed to the effects the authors observed in their mice is not clear. The authors indicate that statins reportedly affect mineralization and bone metabolism by augmenting the expression of bone morphogenic protein-2 (BMP-2). This result could be related to reduced prenylation of RhoA in response to statins [9]. Such a mechanism could have been operative in the $A b c c 6^{-1-}$ mice.

Future experiments investigating the effects of atorvastatin on the functions of ABCC6 are needed. The protein is largely expressed in the liver and the kidney, so that the vascular effects of gene deletion are surprising. ABCC6 resides in the basolateral plasma membrane of hepatocytes, mediating the sinusoidal efflux of unknown metabolites from the hepatocytes to the systemic circulation [10]. A recent study has also suggested a role of endoplasmic reticulum chaperones in cellular trafficking [11]. The findings of Guo et al. [8] are interesting; however, further studies are necessary to provide mechanistic answers.

Respectfully, Friedrich C. Luft

\section{References}

1. Chassaing N, Martin L, Calvas P, Le Bert M, Hovnanian A (2005) Pseudoxanthoma elasticum: a clinical, pathophysiological and genetic update including 11 novel ABCC6 mutations. J Med Genet 42: 881-892

2. Struk B, Cai L, Zach S, Ji W, Chung J, Lumsden A, Stumm M, Huber M, Schaen L, Kim CA et al (2000) Mutations of the gene encoding the transmembrane transporter protein $\mathrm{ABC}-\mathrm{C} 6$ cause pseudoxanthoma elasticum. J Mol Med 78:282-286

3. Le Saux O, Urban Z, Tschuch C, Csiszar K, Bacchelli B, Quaglino D, Pasquali-Ronchetti I, Pope FM, Richards A, Terry S et al (2000) Mutations in a gene encoding an ABC transporter cause pseudoxanthoma elasticum. Nat Genet 25:223-227

4. Le Saux O, Beck K, Sachsinger C, Silvestri C, Treiber C, Goring HH, Johnson EW, De Paepe A, Pope FM, Pasquali-Ronchetti I et al (2001) A spectrum of ABCC6 mutations is responsible for pseudoxanthoma elasticum. Am J Hum Genet 69:749-764

5. Pfendner EG, Vanakker OM, Terry SF, Vourthis S, McAndrew PE, McClain MR, Fratta S, Marais AS, Hariri S, Coucke PJ et al (2007) Mutation detection in the ABCC6 gene and genotype-phenotype analysis in a large international case series affected by pseudoxanthoma elasticum. J Med Genet 44:621-628

6. Trip MD, Smulders YM, Wegman JJ, Hu X, Boer JM, ten Brink JB, Zwinderman AH, Kastelein JJ, Feskens EJ, Bergen AA (2002) Frequent mutation in the ABCC6 gene (R1141X) is associated with a strong increase in the prevalence of coronary artery disease. Circulation 106:773-775

7. Aranyi T, Bacquet C, de Boussac H, Ratajewski M, Pomozi V, Fulop K, Brampton CN, Pulaski L, Le Saux O, Varadi A (2013) Transcriptional regulation of the ABCC6 gene and the background of impaired function of missense disease-causing mutations. Front Genet 4:27

8. Guo H, Li Q, Chou DW, Uitto J (2013) Atorvastatin counteracts aberrant soft tissue mineralization in a mouse model of pseudoxanthoma elasticum $\left(A b c c 6^{-/}\right)$. J Mol Med. doi:10.1007/ s00109-013-1066-5

9. Horiuchi N, Maeda T (2006) Statins and bone metabolism. Oral Dis 12:85-101

10. Pomozi V, Le Saux O, Brampton C, Apana A, Ilias A, Szeri F, Martin L, Monostory K, Paku S, Sarkadi B et al (2013) Abcc6 is a basolateral plasma membrane protein. Circ Res 112:e148-e151

11. Le Saux O, Martin L, Aherrahrou Z, Leftheriotis G, Varadi A, Brampton CN (2012) The molecular and physiological roles of ABCC6: more than meets the eye. Front Genet 3:289 